chine, like the famous statue of the tyrant of Agrigentum, seizes the patient by all his limbs, and forces him to remain motionless, no matter to what operations he is subjected.-Lanc. Franc.

MEdical Mission to poland and nussia.

Ar the Academie de Medicine, May 17, the President read a ministerial letter inviting the Academie to elect several physicians and surgeons to be sent into Poland and Russia at the expense of the state. In this letter the eruption of the cholera morbus in Puland is declared, and the object of the mission is stated to be for the purpose of observing the nature and means of treating this epidemic. Four physicians and two surgeous were required for Poland; two physicians and one surgeon for Russia. The Russian and Prussian authorities have pro. mised assistance and protection to the proposed embassy.

\section{MR. NEVILLE'S FRACTURE APPARATUS.}

\section{To the Editor of THE LANCET.}

Sin,-Having a short time since been thrown out of a chaise, I broke the tibia and fibula of my right leg. At first I had the fract ure treated with the old-fashioned wood. den splints, but heariug of Mr. Neville's newly-invented leg-splints, the surgeon who was in attendance procured them on the fourth day. On examining my leg, however, three weeks afterwards, he observed that the fibula had not been kept in its proper position by the side-splints; for which reason I do not consider the side-splints to he of sufficient strength and breadth; I have, theretore, had the old ones replaced. Now, Sir, in my humble opinion, if the sidesplints were constructed after the same fashion as the anterior or upper splints, ouly a little broader, it would be of great service to fractured legs, and this I beg to suggest to Mr. Neville, and am

Sir, your humble servant,

A Suffering Medical Student

April $27 \mathrm{th}, 1831$.

\section{MR. WALLER'S PRIZES.}

\section{To the Editor of THE LANCET.}

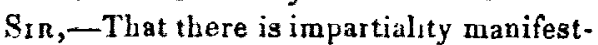
ed by most of the teachers at the Medical School, Aldersgate Street, in awarding their prizes, cannot be denied; and why Mr. Waller's is rot conducted upon the system adopted by his colleagues, is to me an enigma; for a more unequal examination never occurred in a medical establishment.
You are not, perhaps, aware, that the successful candidate of this year, and who emblazoned the sheets of the last week's LANCET, had been studying midwifery more than three years at this metropolis under Mr. Waller; yes, and to confirm the truth of this assertion, I will give you a correct list of candidates, and the periods at which they commenced their obstetrical career. The examination took place on the $2 \mathrm{~d}$ of this month, when the following gentlemen took their seats :-

Mr. ALGER, attended cases and lectures in the year 1828 .

Mr. Burchett, a licentiate of the Apothecaries' Hall, five courses of lectures, and not less than 60 cases.

Mr. Dy ER, attended lectures and cases in the early part of the year 1829 .

Mr. GEE, attended cases and lectures since January 1831.

Mr. SearLe, attended cases and lectures in the year 1830.

Thus you see that it matters not how long a pupil may have been studying this branch, neither does it signify whether he be an M.D., F.R.C.S., or a licentiate of the apathecaries' Hall, so that he is but a pupil. This the lecturer himself cannot refute, as it has been verified this season.

And now I would ask what praise is due to this indefatigable prizer, for the examiners themselves admitted that there was but a shade of difference, and that even Mr. Gee, who had only attended one course, had the highest eneomiums conferred upon his industry, having the greater number of capital answers. ${ }^{*}$ It is, therefore, evident, that the honour was conferred upon Mr. Alger, not for industry and talent, but merely be. cause he was an old pupil; for it is clear enough that his experience only made up for his industry, or why was he not a candidate the first season?

In concluding, Sir, I have only to state, that you will greatly oblige the industrious by having this abuse corrected, which may easily be accomplished, by confining the honour to those of the first season.

I am, Sir, your obedient servant, E. L.

\section{REMUNERATION FOR MEDICAL} ATTENDANCE.

\section{To the Editor of ThE LANCET.}

SiR,-It bas been for some time past matter of surprise to me, that after so much has been said relative to the mode of remu-

* The answers were all equally numbered or valtued. 
nerating medical men, the old fashion of giving attendance gratuitously, and sending a large and unnecessary quantity of medicine at an exorbitant price, by way of recompense, should still be adhered to. This, I believe, is not to be attributed to disinclination on the part either of the public or the profession to making an alteration, but is owing to inattention to the subject on the part of the former, and to fear among individuals composing the latter, lest, in attempting to make an alteration, their practice should suffer. That this fear is without foundation, a short account of my own proceedings relative to this subject, I hope, will prove.

In April 1829, when I commenced practice alone, having separated from a gentleman with whom I had previously been in partnership, I determined, if possible, to make an alteration in the mode of receiving remuneration for my services, and to charge for my visits, instead of depending upon the price of my medicine for compensation. As this was at that time almost an unbeard-of plan in London, I began very cautiously. I first made special agreements with those of my patients who were my personal friends, and afterwards with others. Finding no objections made to my proposals, I next began to charge in my bills for visits, in. cluding medicine in the amount, without any special agreement, taking care, however, that my charge for visits should never much exceed what, according to the old mode, would have been made for medicine. Since Christmas 1829, I have continued the same plan, charging a certain sum for a visit, and making no difference whether the patient took a single pill or half a dozen draughts. By this mode my patients are satisfied that the medicine $I$ send them is only such as it is intended they should take, I having no interest in sending more than is necessary; and, on my part, having nothing to think of when prescribing but what will most benefit my patients, I am not obliged to rack my brains to consider into bow many draughts I can divide a dose of Epsom salts, how many leeches I can persuade my patients to bear, and whether they will submit to an unnecessary blister or two. I should think that little need be said to convince the most superficial observer, that the patient's case must receive much more attention from the medical attendant when these considera. tions are not regarded. I have now acted on this plan about two years, and am not aware that I have ever lost a patient in consequence. I am likewise acquainted with other medical men who act in a somewhat similar way, and whose reports are equally farourable. Having, I hope, said enough to show that it is in the power of any indiridual to make the desired altera- tion without the concurrence of others, I shall in the next place proceed to consider the particular mode in which this is to be effected.

Your correspondent Chirurgus, in ThE LANCET of the $2 d$ instant, appears to think the only eligible mode to be, making a contract to attend families by the year. This plan, however, can only be carried into effect in a limited number of cases. Families who have recently taken up their abode in a neighbourhood, and those who who are nut likely to stay for any long period, will not be likely to engage a medical man by the year; and there are inany who will be afraid their medical attendant will be less attentive, when be receives the same pay whatever duty he may be required to perform. Some medical friends of mine make a low charge for medicine, and send only what the patient requires, making up the difference by charging for attendauce; but I fear this plan, if generally followed, would bring us back in a short time to the present practice. Many young men upon their beginning business, and others who find a difficulty in obtaining practice, would offer their services without charging for attendance, represeuting that patients would be at so much less expense, though they might, at the same time, make up the difference by the quantity of medicine they sent. I think, therefore, when it does not suit the parties to engage a medical man by the year, the best plan is to charge by the visit, and to make such a charge as shall render it unnecessary to charge for medicine at all. Upon this plan a patient knows what expense he is going to when employing a medical man, and is not surprised, at the termination of his illness, by an enormous bill for draughts which were never intended to be taken, pills that have been thrown away, \&c. \&c.

The next point to be considered, relative to this subject, is the amount to be charged per visit. As to combinations of medical men for fixing charges, and obliging the members of the profession to abide by their regulations, I think them as absurd in theory as impossible in practice. It must be evi. dent that if all medical men were obliged to make the same charges, those whose reputation does not stand very high would have no business, while those in whom the public place greater confidence would have all the patients. I think, however, that a general expression of the opinion of the profession, as to what charges would be equivalent to the present mode of receiving remuneration in the form of payment for medicine, would be of great service, leaving it afterwards to individuals to fix their own fees according to the estimation in which 
they found their services were held by the public.

In my own case $I$ have considered five shillings a visit a fair remuneration; and when my patieuts have only a limited income, or are burdened with a large family. I am satisfied with three-and-sixpence, and in some cases still less: when they come to me before $I$ leave home in the morning, I consider half-a-crown a full charge. In fact, I consider the exertions of medical men a public benefit, to be supported, upon the same plan as a national geverument, by all, according to their means, every one receiving the same care and attention when his case requires it.

It has been objected to me that my fees do not equal what others are in the babit of receiving in the old way; but being unsupported by my neighbours, I thought it necessary to make such a charge as would convince my patients they were not paying me more than another medical man would charge. When, however, allowance is made for the saving of time, bottles, and medicine, in sending a six-ounce mixture instend of six draughts, and in sending no more medicine than is necessary, the loss to medical men will not appear so great.

I am, Sir,

Your most obedirnt servant, Josepu Curtis, M.R.C.S.

Camden Town, April 2\%, 1831.

m. keate's letter to ma. king.

\section{To the Editor of The Lancet.}

Sin,-You ask me whether you had any knowledge of the letter addressed to me by Mr. Keate, in which it is intimated that something would be done to induce the Lords of the Admiralty to rescind the order complained of by the members of the College of Surgeons? Most certainly you had nol. Mr. Keate wished me to consider it a private and confidential communication. I did so in the most sacred sense of the terms.

It is singular enough, that although $I$ applied to him several times for permission to publish that letter, he eonstantly declined granting it; but if really the Council wished the commonalty to know that they (the Council) were interfering on behalf of the naval surgeons, why did they not state it at once? As I told Mr. Keate, I had nothing to do with any person or persons assembled at the Colle $e$, I ouly acted as an individual after the resolution was presented to tim, and his answer returned. That answor was to the purport, that the Council could not iuterfere, because our proceedings at the College were irregular. Allow me to take this opportunity of ex borting yon to use temperate language in your further efforts to ameliorate the state of the profession, and believe me to remain consistently yours,

P. S. Do not forget th strength.

Thursday evening, 10, Hanover St., Hanover Sq.

NEW POISON AND ENEMA SYRINGE,*

Mr. Gray, the surgical instrument-maker of Prince's Street, has submitted to our in. spection an instrument under the above name, more generally known as a stomach. pump, which he has lately constructed, and is endeavouring to introduce to the notice of the profession. We shall not atiempt to give a description of it, for without an en. graving it would not be easy to explain the construction; but as our opinion has been requested on it, we do Mr. Gray the justice to state that it is a model of simplicity, and in operation is equal to any instrument of the kind we have yet seen. To these recommendations the maker has added an. other-lowness of price. The instrument before us is very beautifully made, is accompanied by all the necessary appendages for its use, and is enclosed in a good ma. hogany case at the price, we are informed, of thirty-five shillings. So well-manufac. tured, efficient, meritorious, and cheap an apparatus, we have seldom inspected; and considering it well worthy the notice of medical practitioners, we recommend it to their attention.

* From a highly respectable correspondent, on whose judgment we can rely.

\section{TO CORRESPONDENTS.}

We beg to acknowledge the receipt of the courteous letter of our correspondent at Louth. We shall be happy again to meet with him at an carly day in the field of medical literature.

A Subscriber to TuE LANCE'T, cannot practise as be describes without the license. The city freedom is not necessary.

Qucesitor. It is not legal to do so.

Let A General Practitioner, Fleet Street, put his name to his letter and it shall be published.

The publication of Tria Juncta in Unn, would give offence in a quarter which the writer did not probably intend it to reach.

S. $\boldsymbol{H}$. W. cannot for a moment seriously expect us to enterlain the proposition he has made.

We have not seen the letter of Mr. Francis White of Dublin, and cannot, therefore, tell whether the strictures of $\boldsymbol{A}$ Medica $\boldsymbol{l}$. Student are justified, which, at any rate, would be more appropriately published in the paper in question.

The letters respecting Mr. Guthrie's lectures next week. 